\title{
Reproducibility of parameters of postocclusive reactive hyperemia measured by diffuse optical tomography
}

Ernesto E. Vidal-Rosas

Stephen A. Billings

Timothy Chico

Daniel Coca 


\title{
Reproducibility of parameters of postocclusive reactive hyperemia measured by diffuse optical tomography
}

\author{
Ernesto E. Vidal-Rosas, ${ }^{a}$ Stephen A. Billings, ${ }^{a}$ Timothy Chico, ${ }^{b}$ and Daniel Coca ${ }^{a, *}$ \\ anniversity of Sheffield, Department of Automatic Control and Systems Engineering, Mappin Street, Sheffield S1 3JD, United Kingdom \\ bUniversity of Sheffield, Department of Cardiovascular Science, Western Bank, Sheffield S10 2TF, United Kingdom
}

\begin{abstract}
The application of near-infrared spectroscopy (NIRS) to assess microvascular function has shown promising results. An important limitation when using a single source-detector pair, however, is the lack of depth sensitivity. Diffuse optical tomography (DOT) overcomes this limitation using an array of sources and detectors that allow the reconstruction of volumetric hemodynamic changes. This study compares the key parameters of postocclusive reactive hyperemia measured in the forearm using standard NIRS and DOT. We show that while the mean parameter values are similar for the two techniques, DOT achieves much better reproducibility, as measured by the intraclass correlation coefficient (ICC). We show that DOT achieves high reproducibility for muscle oxygen consumption (ICC: 0.99), time to maximal $\mathrm{HbO}_{2}$ (ICC: 0.94), maximal $\mathrm{HbO}_{2}$ (ICC: 0.99), and time to maximal $\mathrm{HbT}$ (ICC: 0.99 ). Absolute reproducibility as measured by the standard error of measurement is consistently smaller and close to zero (ideal value) across all parameters measured by DOT compared to NIRS. We conclude that DOT provides a more robust characterization of the reactive hyperemic response and show how the availability of volumetric hemodynamic changes allows the identification of areas of temporal consistency, which could help characterize more precisely the microvasculature. $\odot$ The Authors. Published by SPIE under a Creative Commons Attribution 3.0 Unported License. Distribution or reproduction of this work in whole or in part requires full attribution of the original publication, including its DOI. [DOI: 10.1117/1.JBO.21.6.066012]
\end{abstract}

Keywords: diffuse optical tomography; near-infrared spectroscopy; reproducibility.

Paper 150837R received Dec. 28, 2015; accepted for publication May 9, 2016; published online Jun. 15, 2016.

\section{Introduction}

Atherosclerosis and resulting cardiovascular diseases such as stroke and myocardial infarction are a major cause of death in developed countries. These account for more than $32 \%$ of mortality worldwide, ${ }^{1}$ and in England and Wales cardiovascular disease was responsible for almost $30 \%$ of deaths in $2011 .^{2}$ Many noninvasive methods have been developed to assess the peripheral vascular system and identify signs of atherosclerosis at an early stage. Optical methods, in particular, have received attention due to their capability of measuring tissue oxygenation and blood perfusion ${ }^{3,4}$ and because they offer several attractive features, such as portability, compactness, fast data acquisition, and noninvasiveness.

Near-infrared spectroscopy (NIRS) can determine changes in tissue hemodynamics and oxygenation ${ }^{5,6}$ by measuring tissue absorbance at several wavelengths in the near-infrared range of the electromagnetic spectrum (650 to $950 \mathrm{~nm}$ ). Typically, NIRS employs a few source-detector pairs to carry out measurements. As a consequence, the spatial resolution of NIRS, which is dictated by the optode separation, is relatively low. ${ }^{7}$ Diffuse optical tomography (DOT) overcomes this limitation by employing a larger number of sources and detectors to enable three-dimensional (3-D) volumetric reconstruction ${ }^{8}$ of changes in tissue hemodynamics.

NIRS and DOT have been used in a wide range of applications including functional imaging of the brain, ${ }^{9}$ assessment of

\footnotetext{
*Address all correspondence to: Daniel Coca, E-mail: d.coca@sheffield.ac.uk
}

muscle oxygenation, ${ }^{10}$ and cancer detection. It is widely accepted that DOT outperforms NIRS. ${ }^{8,11}$ For example, localized changes in hemodynamics due to motor tasks in adults and motor-sensory brain activation in neonates were accurately measured using DOT, while NIRS could not even detect relative changes $^{11}$ because of low spatial sampling. In another study, DOT could discriminate the somatosensory activation of two fingers, while in the same experiment, a 12-channel NIRS setting failed to resolve the activation. ${ }^{12}$ Among the factors affecting the accuracy of NIRS concentration calculations are the differences in the pathlength factor: location, spatial extent, and heterogeneous distribution of absorption changes, e.g., multiple absorption foci. Although these sources of error could be minimized, ${ }^{13}$ DOT accounts for these problems implicitly. ${ }^{7}$

DOT requires solving two distinct problems: the forward problem and the inverse problem. The forward problem requires solving of the equation governing the photon transport in tissue to predict the detector measurements; typically this involves solving a diffusion equation over a 3-D spatial domain using the finite element method. The inverse problem involves estimating the optical properties of tissue to minimize the difference between experimental and model-predicted measurements; this is achieved by solving a nonlinear optimization problem, which can take hours to complete even on a high-end workstation. However, as we have recently demonstrated, ${ }^{14}$ it is possible to significantly speed up reconstruction of hemodynamic changes in complex tissue structures by using reduced order models of photon transport in tissue. This makes it possible 
to perform real-time monitoring of hemodynamic responses even with relatively modest computing resources.

NIRS, like other methods of measuring microvascular function, can detect significant differences in microvascular function between groups of healthy controls and patients with peripheral vascular diseases, ${ }^{15-17}$ peripheral artery disease (PAD), and coronary heart disease. ${ }^{17-19}$ However, these techniques are highly variable and have not been shown to be helpful in predicting an individual's risk of future cardiovascular disease. Therefore, from a clinical point of view, refinements that improve reproducibility and reduce variability are highly desirable.

Typically, the evaluation of microvascular function by NIRS relies solely on a few measuring channels, and although repeatability and accuracy of results are promising, ${ }^{18,20,21}$ there has not been a direct comparison of the parameters obtained during and after arterial occlusion by NIRS versus DOT. Furthermore, while multichannel systems for analysis of microvascular function are available, ${ }^{22-25}$ studies on repeatability are lacking.

This study aims to evaluate and compare, using experimental data collected from healthy volunteers, the intrasubject reproducibility of key parameters of the hemodynamic response during postocclusive reactive hyperemia, obtained using DOT and NIRS, and to highlight the potential advantages of DOT in assessing endothelial function.

\section{Methods}

\subsection{Subjects}

This study was approved by the Research Ethics Committee of the University of Sheffield. A group of 17 subjects was recruited, after giving informed consent. The group consisted of 11 men and 6 women. Baseline characteristics are listed in Table 1. Smokers or those with a history of cardiovascular disease were excluded.

It is known that measurement of vascular function is greatly influenced by external factors such as recent activity, diet, time of day, and so on. These influences greatly reduce the applicability of vascular function measurement to clinical practice since in the real world it is difficult or impossible to control these factors. For this reason, we did not ask participants to fast or refrain from physical activity or caffeine for either of their visits.

\subsection{Instrumentation}

DOT and NIRS measurements were obtained using a dynamic near-infrared optical tomography (DYNOT) instrument (NIRx). The system illuminates the tissue with four laser diodes at wavelengths $\lambda=725,760,810$, and $830 \mathrm{~nm}$.

Table 1 Baseline characteristic of study subjects $(n=17)$.

\begin{tabular}{lc} 
Characteristic & Values \\
\hline Age (year) & $33 \pm 7.5$ \\
Weight $(\mathrm{kg})$ & $70.5 \pm 14.1$ \\
Height $(\mathrm{cm})$ & $172.1 \pm 8.3$ \\
BMl $\left(\mathrm{kg} / \mathrm{m}^{2}\right)$ & $23.6 \pm 3.4$ \\
Smokers & 0 \\
\hline
\end{tabular}

The diodes are modulated at distinct frequencies and then coupled with $30,1 \mathrm{~mm}$ multimode optical fibers-optodesacting both as sources and detectors. Synchronous detection allows parallel measurement at a sampling frequency of $1.8 \mathrm{~Hz}{ }^{26}$ The optodes were organized in a hexagonal pattern with an interoptode spacing of $8 \mathrm{~mm}$ as shown in Fig. 1(a) and placed in a solid plastic holder to avoid movement artifacts [Fig. 1(b)]. For simplicity, hemoglobin concentration was calculated using only the wavelengths at 760 and $830 \mathrm{~nm}$, chosen based on their symmetry with respect to the isobestic point of the extinction coefficients of hemoglobin.

\subsection{Near-Infrared Spectroscopy}

NIRS employs the modified Beer-Lambert law (MBLL)

$\mathrm{OD}=-\log \frac{I}{I_{0}}=\varepsilon \mathrm{CLB}+G$

to convert from changes in absorption to changes of de/oxyhemoglobin. ${ }^{5,27}$ In Eq. (1) OD is the optical density and $I_{0}$ and $I$ are incident and detected light intensities, respectively. $\varepsilon$ represents the extinction coefficient of the tissue, and $C$ is the concentration of the chromophore. $L$ denotes the mean path length of detected photons. $B$ is the path length factor, which accounts for the compensation of the increase of path lengths at various wavelengths caused by the scattering phenomena. $G$ is defined as a geometric factor used to compensate the objective with different geometrical shapes. Typically, $L, B$,

(a)

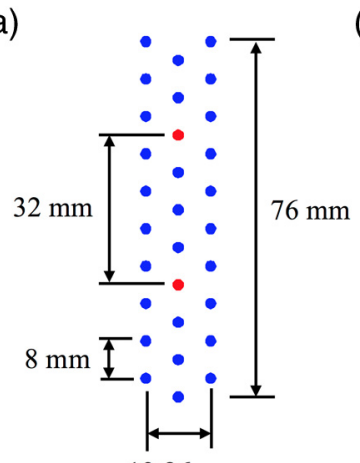

$13.86 \mathrm{~mm}$

(c)

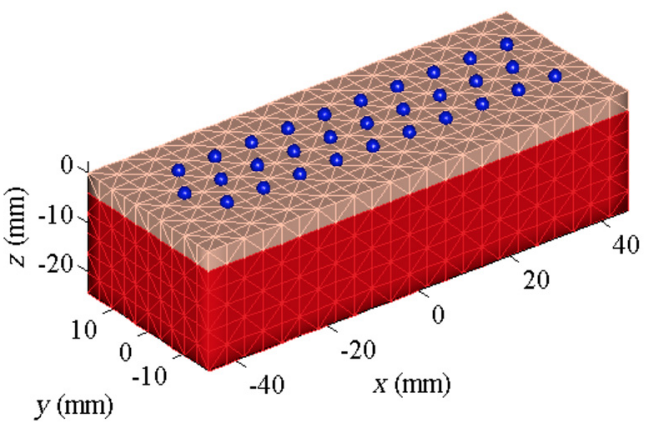

Fig. 1 Experimental setup for NIRS and DOT measurement of reactive hyperemia. (a) Array with 30 optodes placed $8 \mathrm{~mm}$ apart in a hexagonal pattern. Optodes in red were used for NIRS measurements. All optodes were used for DOT reconstructions. (b) Placement of optode array on volar forearm of subject. (c) Rectangular finite element mesh used to model forearm tissue with dimensions $92 \mathrm{~mm} \times 35 \mathrm{~mm} \times 24 \mathrm{~mm}(W \times L \times D)$. Blue circles at $z=0 \mathrm{~mm}$ indicate the location of the 30 optodes. 
and $G$ are constants with monochromatic illumination in a turbid media with unchanging geometry.

A change in the concentration of the chromophore causes a change in the intensity measured. The parameters $\varepsilon$ and $L$ remain constant, and it is assumed that $B$ and $G$ remain constant. Under this assumption, Eq. (1) can be written as

$$
\Delta \mathrm{OD}=\mathrm{OD}_{\text {Final }}-\mathrm{OD}_{\text {Initial }}=-\log \frac{I_{\mathrm{f}}}{I_{\mathrm{i}}}=\varepsilon \Delta \mathrm{CLB},
$$

where $\Delta \mathrm{OD}$ is the change in optical density. $\mathrm{OD}_{\text {Final }}$ and $\mathrm{OD}_{\text {Initial }}$ are the detected optical density and the optical density of incident light. $I_{\mathrm{f}}$ and $I_{\mathrm{i}}$ are the measured intensities before and after the change in concentration; $\Delta C$ is the change in concentration. In Eq. (2), $B$ is often referred to as the differential pathlength factor $^{28}$ (DPF). DPF was determined experimentally for a number of tissues including forearm, calf, adult, and infant head. ${ }^{29}$ Changes in detected light are dominated mainly by oxygenated $\left(\mathrm{HbO}_{2}\right)$ and deoxygenated hemoglobin $(\mathrm{HbR})$ such that

$$
\Delta \mathrm{OD}^{\lambda}=\left(\varepsilon_{\mathrm{HbO}_{2}}^{\lambda} \Delta\left[\mathrm{HbO}_{2}\right]+\varepsilon_{\mathrm{HbR}}^{\lambda} \Delta[\mathrm{HbR}]\right) B^{\lambda} L,
$$

where $\varepsilon_{\mathrm{HbO}_{2}}^{\lambda}, \varepsilon_{\mathrm{HbR}}^{\lambda}, B^{\lambda}$ are the extinction coefficients for oxyhemoglobin and deoxyhemoglobin and DPF at a given wavelength. By measuring the change in intensity at two wavelengths, it is possible to determine the concentration changes in $\mathrm{HbO}_{2}$ and $\mathrm{HbR}$

$$
\begin{aligned}
\Delta[\mathrm{HbR}] & =\frac{\varepsilon_{\mathrm{HbO}_{2}}^{\lambda 2} \frac{\Delta \mathrm{OD}^{\lambda 1}}{B^{\lambda 1}}-\varepsilon_{\mathrm{HbO}_{2}}^{\lambda 1} \frac{\Delta \mathrm{OD}^{\lambda 2}}{B^{\lambda 2}}}{\left(\varepsilon_{\mathrm{HbR}}^{\lambda 1} \varepsilon_{\mathrm{HbO}_{2}}^{\lambda 2}-\varepsilon_{\mathrm{HbR}}^{\lambda 2} \epsilon_{\mathrm{HbO}_{2}}^{\lambda 1}\right) L}, \\
\Delta\left[\mathrm{HbO}_{2}\right] & =\frac{\varepsilon_{\mathrm{HbR}}^{\lambda 1} \frac{\Delta \mathrm{OD}^{\lambda 2}}{B^{\lambda 2}}-\varepsilon_{\mathrm{HbR}}^{\lambda 2} \frac{\Delta \mathrm{OD}^{\lambda 1}}{B^{\lambda 1}}}{\left(\varepsilon_{\mathrm{HbR}}^{\lambda 1} \varepsilon_{\mathrm{HbO}_{2}}^{\lambda 2}-\varepsilon_{\mathrm{HbR}}^{\lambda 2} \varepsilon_{\mathrm{HbO}_{2}}^{\lambda 1}\right) L} .
\end{aligned}
$$

Typical source-detector separations in NIRS studies in reflectance mode are in the range 20 to $50 \mathrm{~mm}$. NIRS measurements taken with the DYNOT equipment for separations larger than $45 \mathrm{~mm}$ were noisy $(\mathrm{CV}>5 \%)$, therefore this study was limited to a source-detector separation of $L=32 \mathrm{~mm}$ obtained by selecting the central fibers indicated with red circles in Fig. 1(a). Although DPF depends on inter-optode spacing and wavelength, experiments carried out in the forearm suggest that this parameter becomes constant for distances larger than $25 \mathrm{~mm} .{ }^{29-31}$ For this study, DPF $=4.0$ was used for the calculation of concentration changes.

\subsection{Diffuse Optical Tomography}

Photon transport in tissue was modeled using the diffusion approximation of the radiative transport equation. ${ }^{32,33}$ This is a more accurate description of photon transport than the MBLL because it takes into account the random scattering of light produced by tissue. Consider the medium $\Omega \subset \mathbb{R}^{3}$ with boundary $\partial \Omega$, the diffusion equation in the steady-state domain is

$$
-\nabla D(r) \nabla \phi_{i}(r)+\mu_{a}(r) \phi_{i}=q_{i}(r), \quad r \in \Omega,
$$

where $\phi_{i}(r)$ is the spatially varying photon fluence at $r$ due to source $q_{i}, \mu_{\mathrm{a}}$ is the absorption coefficient, $D=\left[3\left(\mu_{\mathrm{a}}+\mu_{\mathrm{s}}^{\prime}\right)\right]^{-1}$ is the diffusion coefficient, and $\mu_{\mathrm{s}}^{\prime}$ is the reduced scattering coefficient. The source term represents an isotropic point source $q_{i}(r)=\delta\left(r-r_{i}\right)$ located at a depth of one scattering length inside the medium $\left(d=1 / \mu_{\mathrm{s}}^{\prime}\right)$. The boundary condition is usually of Robin type ${ }^{34}$

$D(\xi) \frac{\partial \phi_{i}(\xi)}{\partial n}+\frac{1}{2 A} \phi_{i}(\xi)=0, \quad \xi \in \partial \Omega$,

where the term $A$ accounts for the refractive index boundary mismatch at the interface. The quantity measured by a detector located at $\xi_{j} \in \partial \Omega$, given the point source $q_{i}(r)$, is the outward flux $\Gamma_{i}\left(\xi_{j}\right)$, and it is calculated from Fick's law

$\Gamma_{i}\left(\xi_{j}\right)=-D\left(\xi_{j}\right) \vec{n}\left(\xi_{j}\right) \cdot \nabla \phi_{i}\left(\xi_{j}\right), \quad \xi_{j} \in \partial \Omega$,

where $\vec{n}\left(\xi_{j}\right)$ denotes the direction of the normal vector to the boundary at the detector location $\xi_{j}$. Equations (5)-(7) constitute the forward problem in DOT, which can also be represented by a scalar operator mapping ${ }^{35}$ between the space of optical parameters of interest, $\mu_{\mathrm{a}}$ in this case, and the space of measurements as

$y_{i, j}=\Gamma_{i}\left(\xi_{j}\right)=P_{i, j}\left[\mu_{\mathrm{a}}(r)\right], \quad r \in \Omega$,

where $y_{i, j}$ is the output of the $j$ 'th detector given the source $i$.

\subsubsection{Image reconstruction}

3-D volumetric reconstruction of the absorption coefficient was carried out using a modified version of the normalized difference approach proposed by Pei et al. ${ }^{36}$ At each sampling time $t_{k}$, the 3-D absorption coefficient map $\mu_{\mathrm{a}}\left(r, t_{k}\right)=$ $\mu_{\mathrm{a}_{\mathrm{ref}}}(r)+\Delta \mu_{\mathrm{a}}\left(r, t_{k}\right)$, discretized over the 3-D mesh, is determined by minimizing, using a nonlinear conjugated-gradient algorithm, ${ }^{37}$ the following cost function ${ }^{38}$

$$
F=\sum_{r_{l \in \Omega}} \sum_{i=1}^{N_{s}} \sum_{j=1}^{N_{d, i}}\left\{\frac{\frac{y_{i, j}\left(t_{k}\right)}{y_{i, j}^{0}} \hat{P}_{i, j}\left[\mu_{\mathrm{a}_{\mathrm{ref}}}\left(r_{l}\right)\right]-\hat{P}_{i, j}\left[\mu_{\mathrm{a}}\left(r_{l}, t_{k}\right)\right]}{\frac{y_{i, j}\left(t_{k}\right)}{y_{i, j}^{0}} \hat{P}\left[\mu_{\mathrm{a}_{\mathrm{ref}}}\left(r_{l}\right)\right]}\right\}^{2}
$$

The first summation in the right side of Eq. (9) is over the volume elements of the 3-D mesh. In Eq. (9), $N_{\mathrm{s}}$ is the total number of sources, $N_{d, i}$ is the number of detectors for the $i$ 'th source, $y_{i, j}\left(t_{k}\right)$ is the flux measured by the $j$ 'th optode given the source $i$ at time $t_{k}, y_{i, j}^{0}$ is a reference state defined as the mean of the baseline measurements, and $\hat{P}_{i, j}\left[\mu_{\mathrm{a}_{\mathrm{ref}}}(r)\right]$ and $\hat{P}_{i, j}\left[\mu_{\mathrm{a}}\left(r, t_{k}\right)\right]$ are the model predicted measurements for the reference and estimated absorption coefficient at time $t_{k}$. Essentially, for each time sample, the initial guess in the optimization process is the reference state $\mu_{\mathrm{a}_{\mathrm{ref}}}(r)$. The conjugate gradient descent algorithm is applied iteratively for $n$ steps to compute the estimate $\mu_{\mathrm{a}}\left(r, t_{k}\right)$. Note that the optimized image from a previous time sample can be used also as the initial guess. However, in this paper, concentration calculations were carried out independently of previous or subsequent samples.

\subsubsection{Calculation of hemoglobin concentration}

The absorption coefficient is related to the extinction coefficient and concentration as $\mu_{\mathrm{a}}=\epsilon C$. Assuming that the primary source of absorption changes is a combination of hemoglobin chromophores 
$\Delta \mu_{\mathrm{a}}=\varepsilon_{\mathrm{HbO}_{2}}^{\lambda} \Delta\left[\mathrm{HbO}_{2}\right]+\varepsilon_{\mathrm{HbR}}^{\lambda} \Delta[\mathrm{HbR}]$,

where $\varepsilon_{\mathrm{HbO}_{2}}^{\lambda}$ and $\varepsilon_{\mathrm{HbR}}^{\lambda}$ are the extinction coefficients for oxyhemoglobin and deoxyhemoglobin at a given wavelength. Reconstruction of absorption changes at two different wavelengths provides two independent equations, which can be solved simultaneously to calculate deoxyhemoglobin and oxyhemoglobin concentration changes as

$$
\begin{gathered}
\Delta[\mathrm{HbR}]=\frac{\varepsilon_{\mathrm{HbO}_{2}}^{\lambda 1} \Delta \mu_{\mathrm{a}}^{\lambda 2}-\varepsilon_{\mathrm{HbO}_{2}}^{\lambda 2} \Delta \mu_{\mathrm{a}}^{\lambda 1}}{\varepsilon_{\mathrm{HbO}_{2}}^{\lambda 1} \varepsilon_{\mathrm{HbR}}^{\lambda 2}-\varepsilon_{\mathrm{HbO}_{2}}^{\lambda 2} \varepsilon_{\mathrm{HbR}}^{\lambda 1}} \\
\Delta\left[\mathrm{HbO}_{2}\right]=\frac{\varepsilon_{\mathrm{HbR}}^{\lambda 2} \Delta \mu_{\mathrm{a}}^{\lambda 1}-\varepsilon_{\mathrm{HbR}}^{\lambda 1} \Delta \mu_{\mathrm{a}}^{\lambda 2} .}{\varepsilon_{\mathrm{HbO}_{2}}^{\lambda 1} \varepsilon_{\mathrm{HbR}}^{\lambda 2}-\varepsilon_{\mathrm{HbO}_{2}}^{\lambda 2} \varepsilon_{\mathrm{HbR}}^{\lambda 1}}
\end{gathered}
$$

\subsubsection{Finite element modeling}

A simplified finite element model of the skin and muscle tissue was used to implement the DOT reconstruction algorithms. The tissue was modeled as a rectangular cuboid with two layers [Fig. 1(c)] with dimensions $92 \mathrm{~mm} \times 35 \mathrm{~mm} \times 24 \mathrm{~mm}$ (length $\times$ width $\times$ depth). A tetrahedral mesh with 6900 elements and 1848 nodes [Fig. 1(c)] was generated for this domain. Each layer was assigned realistic optical parameters within the range of clinically normal tissue: $\mu_{\mathrm{a}}=0.01 \mathrm{~mm}^{-1}$ and $\mu_{\mathrm{s}}^{\prime}=1.00 \mathrm{~mm}^{-1}$ for $\operatorname{skin}^{39}$ and $\mu_{\mathrm{a}}=0.02 \mathrm{~mm}^{-1}$ and $\mu_{\mathrm{s}}^{\prime}=0.50 \mathrm{~mm}^{-1}$ for muscle. ${ }^{40}$

A simulation study was carried out to calculate the photon measurement density functions for different source-detector configurations. PDMFs characterize the regions of the tissue that contribute to the measurement signal and can be used to determine a suitable combination of measurements to reconstruct optical properties of tissue within a region of interest (ROI).

It is well known that the sensitivity in the reflectance mode is higher at the surface and diminishes as function of the depth. ${ }^{41,42}$ The study confirmed that for the chosen optode arrangement, depths larger than $\sim 12 \mathrm{~mm}$ contributed less than 5\% to the sensitivity function. As a result, the ROI used in the analysis was a rectangular cuboid with dimensions $80 \mathrm{~mm} \times 20 \mathrm{~mm} \times 12 \mathrm{~mm}$ (length $\times$ width $\times$ depth) as shown in Fig. 2 .

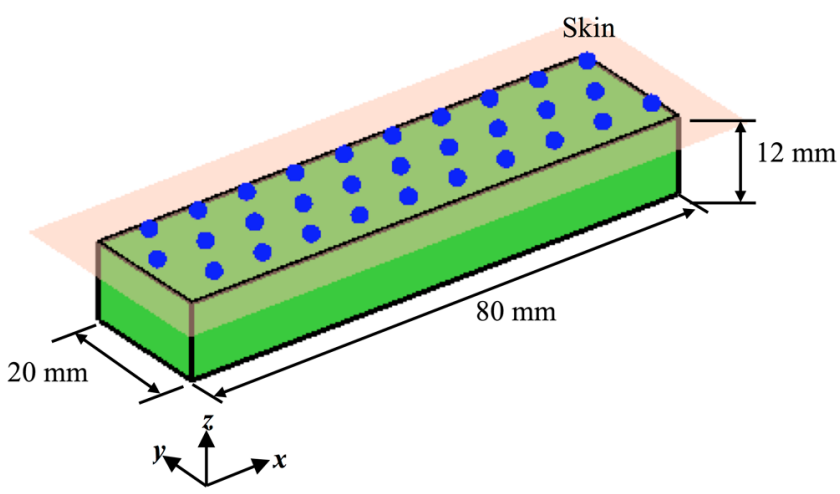

Fig. 2 The ROI is indicated with the volume in green. The location of the optodes in relation to the ROI is indicated with the blue circles. The dimensions of the $\mathrm{ROI}$ are $80 \mathrm{~mm} \times 20 \mathrm{~mm} \times 12 \mathrm{~mm}$ (length $\times$ width $\times$ depth). The ROI is located directly under the array of 30 optodes.
Yu et al. ${ }^{43}$ showed through experiments and simulation studies that for source-detector separations larger than $1 \mathrm{~cm}$, the hyperemic response is mainly influenced by the autoregulation of muscle tissue, while smaller separations are primarily affected by subcutaneous tissue layer. For this reason, firstand second-nearest neighbor source-detector pairs were not used in the reconstruction.

3-D maps of absorption changes were obtained by minimizing the cost function in Eq. (9). To minimize the occurrence of artifacts, a two-step sign constraint algorithm was used during the reconstruction process. ${ }^{44}$ Positivity/negativity constraints were imposed after each iteration in separate reconstructions, and then the final absorption value was calculated as the sum of the two partial solutions. Positivity/negativity constraints force the algorithm to seek only positive/ negative changes in order to minimize the cost function given in Eq. (9). In each case, convergence was usually achieved after 5 to 10 iterations. Pei et al. ${ }^{44}$ demonstrated theoretically and experimentally that by using sign constraints, the quality and specificity of the recovered images improved significantly.

Finally, Eq. (11) was used to compute $\mathrm{HbO}_{2}, \mathrm{HbR}$, and $\mathrm{HbT}$ $\left(\mathrm{HbO}_{2}+\mathrm{HbR}\right)$. Near-infrared parameters of postocclusive reactive hyperemia $(\mathrm{PORH})$ were calculated on a nodal basis and then averaged on the ROI.

\subsection{Study Protocol}

The weight, height, and age for each subject were recorded. The baseline characteristics of the subjects are summarized in Table 1. Microvascular function during forearm PORH was assessed on two different occasions 1 to 2 weeks apart. In order to assess "real-world" performance, subjects were not asked to fast or abstain from exercise, and the time of day of assessment was not standardized. Subjects were requested to sit comfortably on a chair and to locate the right arm on a platform such that the dorsal-ventral axis of the elbow was held parallel to the surface of the platform [Fig. 1(b)]. The hand was placed such that the palm was facing upward. A manual pneumatic blood pressure cuff was placed above the elbow, and the tomographic probe was placed on the ventral side of the forearm on the brachioradialis muscle and attached with tape [Fig. 1(a)].

The test consisted of $3 \mathrm{~min}$ baseline, followed by $5 \mathrm{~min}$ of arterial occlusion (induced by inflating the cuff to $180 \mathrm{mmHg}$ ). After $5 \mathrm{~min}$, the cuff was rapidly deflated and the response measured for a further $5 \mathrm{~min}$ (13 min total measurement time). Light attenuation changes were recorded at the four wavelengths, but only the data at 760 and $830 \mathrm{~nm}$ were used for processing. Hemodynamics changes were calculated using NIRS and DOT techniques. The former uses the MBLL to convert absorption changes into de/oxyhemoglobin ${ }^{5,27}$ [Eq. (4)], while the latter is based in the diffusion process of light [Eqs. (5) and (6)]..$^{35}$

The parameters measured during and after the arterial occlusion test are (Fig. 3):

(i) $\mathrm{mVO}_{2}\left(\mathrm{mlO}_{2} / \mathrm{min} / 100 \mathrm{~g}\right)$, muscle oxygen consumption: calculated from the gradient of the $\mathrm{HbO}_{2}$ at the beginning of the arterial occlusion and converted into $\mathrm{ml} \mathrm{O}_{2} / \mathrm{min} / 100 \mathrm{~g}^{10}$

(ii) $1 / 2 \mathrm{THbO}_{2}$ (s), $1 / 2$ time of recovery of $\mathrm{HbO}_{2}$ : time needed for half recovery of $\mathrm{HbO}_{2}$ from maximum deoxygenation at the end of the occlusion period to maximum reoxygenation during reactive hyperemia. 


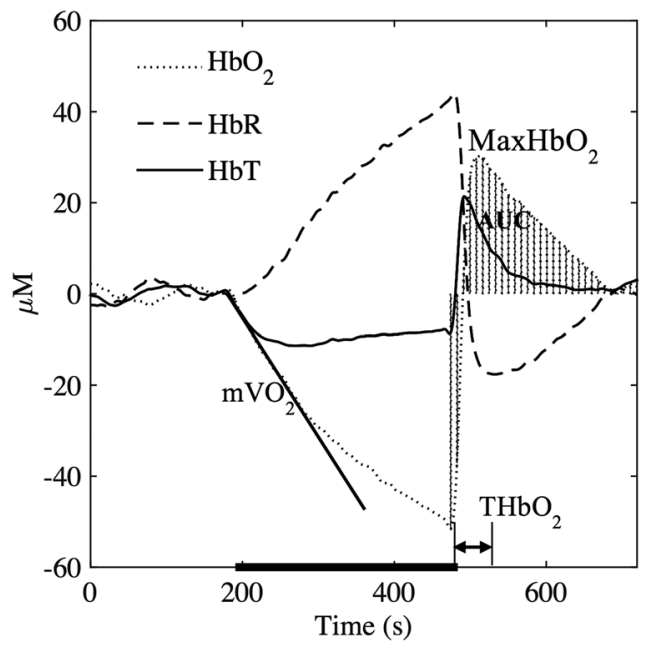

Fig. 3 Typical hemodynamic response before, during, and after 5 min brachial arterial occlusion measured by NIRS. Some characteristic parameters are indicated: oxygen consumption $\left(\mathrm{mVO}_{2}\right)$, maximal amplitude of $\mathrm{HbO}_{2}\left(\mathrm{Max} . \mathrm{HbO}_{2}\right)$, time to maximal of $\mathrm{HbO}_{2}\left(\mathrm{THbO}_{2}\right)$, and area under the curve of $\mathrm{HbO}_{2}$ (AUC).

(iii) $\mathrm{THbO}_{2}(\mathrm{~s})$, time to maximal $\mathrm{HbO}_{2}$ : time interval after cuff release until maximum $\mathrm{HbO}_{2}$ value is reached.

(iv) $\mathrm{MaxHbO}_{2}(\mu \mathrm{M})$, maximal amplitude of $\mathrm{HbO}_{2}$ : maximal hyperemic response reached by $\mathrm{HbO}_{2}$.

(v) MaxHbT $(\mu \mathrm{M})$, maximal amplitude of HbT: maximal hyperemic response of $\mathrm{HbT}$.

(vi) $\mathrm{THbT}(\mathrm{s})$, time to maximal HbT: time to peak value of HbT after cuff release.

(vii) Increase rate to maximal $\mathrm{HbO}_{2}(\mu \mathrm{M} / \mathrm{s})$, reoxygenation rate of $\mathrm{HbO}_{2}$ : calculated by dividing $\mathrm{Max} \mathrm{HbO}_{2}$ by the time to maximal $\mathrm{HbO}_{2}$.

(viii) Increase rate to maximal $\mathrm{HbT}(\mu \mathrm{M} / \mathrm{s})$, reoxygenation rate of $\mathrm{HbT}$ : calculated by dividing Max $\mathrm{HbT}$ by the time and maximal $\mathrm{HbT}$.

(ix) $\mathrm{AUC} \mathrm{HbO}_{2}$ (a.u.), area under the curve of $\mathrm{HbO}_{2}$ after cuff release.

(x) AUC HbR (a.u.), postocclusion area under the curve of $\mathrm{HbT}$.

(xi) AUC HbT (a.u.), area under the curve of $\mathrm{HbT}$ after cuff release.

The reproducibility was assessed using the intraclass correlation coefficient (ICC) and the standard error of measurement $(\mathrm{SEM})^{45}$ based on NIRS parameters measured on two separate occasions. ICC provides the degree to which individuals maintain their rank order across repeated tests, and SEM is a measure of absolute repeatability. To interpret repeatability based on ICC values, the following guidelines were considered: ${ }^{46}$ ICC $\geq 0.8$ indicates "excellent," $0.6 \leq \mathrm{ICC}<0.8$ is defined as "good," $0.4 \leq$ ICC $<0.6$ indicates "moderate," $0.2 \leq \mathrm{ICC}<0.4$ indicates "fair," and ICC $<0.2$ is defined as "poor." On the other hand, SEM is expressed as a percentage and the ideal value is zero. In general, the smaller the SEM, the smaller the variability between individual repeated measurements. ICC was calculated for near-infrared parameters derived using DOT and NIRS, and this is denoted by $\mathrm{ICC}_{\mathrm{DOT}}$ and $\mathrm{ICC}_{\mathrm{NIRS}}$, respectively (similarly for SEM: $\mathrm{SEM}_{\mathrm{DOT}}$ and $\mathrm{SEM}_{\mathrm{NIRS}}$ ).

\section{Results}

\subsection{Microvascular Function Reproducibility}

Table 2 lists the mean and standard deviation of near-infrared parameters, calculated using DOT, during and after the arterial occlusion test, together with ICC and SEM repeatability measures. Similarly, Table 3 displays mean and standard deviation of near-infrared parameters measured using NIRS. Mean values in both tables are very similar; however, the standard deviation for near-infrared parameters derived using DOT is smaller in most cases. More importantly, the $\mathrm{ICC}_{\mathrm{DOT}}$ is higher in all but one case, and the repeatability is extremely high $(\sim 1)$ for $\mathrm{mVO}_{2}, \mathrm{THbO}_{2}, \mathrm{Max}_{\mathrm{HbO}}$, and THbT. In comparison, only one parameter $\left(\mathrm{mVO}_{2}\right)$ measured with NIRS reached the "excellent" ICC category. The least repeatable parameter is AUC HbR, and this is consistent in the two measuring approaches.

SEM calculated for tomographic imaging showed consistently smaller values across all parameters. This suggests that region-wise averaged measurements provide more robust and repeatable measurements than point-wise measurements, as typically measured in NIRS.

\section{Discussion}

Our results are in agreement with similar studies using NIRS; ${ }^{20,47}$ however, the main finding is that tomographic imaging provides more robust and repeatable results. Figure 4 shows the mean and SEM of de/oxyhemoglobin and total hemoglobin across all

Table 2 Intrasubject reproducibility of PORH parameters obtained using DOT.

\begin{tabular}{|c|c|c|c|c|}
\hline Parameter & Test 1 & Test 2 & ICC & SEM \\
\hline $\mathrm{mVO}_{2}$ & $0.07 \pm 0.02$ & $0.07 \pm 0.03$ & 0.99 & 3.90 \\
\hline $1 / 2 \mathrm{THbO}_{2}$ & $14.34 \pm 2.33$ & $15.17 \pm 1.82$ & 0.72 & 7.50 \\
\hline $\mathrm{THbO}_{2}$ & $36.50 \pm 10.44$ & $36.81 \pm 7.70$ & 0.94 & 6.09 \\
\hline $\mathrm{MaxHbO}_{2}$ & $19.99 \pm 6.06$ & $20.01 \pm 7.31$ & 0.99 & 2.85 \\
\hline MaxHbT & $19.21 \pm 5.24$ & $20.09 \pm 6.92$ & 0.69 & 17.31 \\
\hline THbT & $21.63 \pm 13.35$ & $21.71 \pm 7.98$ & 0.99 & 5.98 \\
\hline $\begin{array}{l}\text { Inc. rate to } \\
\max \mathrm{HbO}_{2}\end{array}$ & $1.53 \pm 0.51$ & $1.46 \pm 0.55$ & 0.70 & 19.60 \\
\hline $\begin{array}{l}\text { Inc. rate to } \\
\text { max } \mathrm{HbT}\end{array}$ & $0.72 \pm 0.39$ & $0.62 \pm 0.47$ & 0.51 & 45.16 \\
\hline AUC $\mathrm{HbO}_{2}$ & $1461.79 \pm 572.51$ & $1625.32 \pm 900.88$ & 0.54 & 32.22 \\
\hline AUC HbR & $708.47 \pm 586.48$ & $611.91 \pm 551.93$ & 0.63 & 52.11 \\
\hline AUC $\mathrm{HbT}$ & $1313.68 \pm 963.06$ & $1741.28 \pm 775.31$ & 0.22 & 45.11 \\
\hline
\end{tabular}


Table 3 Intrasubject reproducibility of PORH parameters obtained using NIRS spectroscopy.

\begin{tabular}{lcccc} 
Parameter & Test 1 & Test 2 & ICC & SEM \\
\hline $\mathrm{mVO}_{2}$ & $0.08 \pm 0.06$ & $0.08 \pm 0.04$ & 0.97 & 10.98 \\
$1 / 2 \mathrm{THbO}_{2}$ & $16.57 \pm 11.18$ & $15.64 \pm 3.29$ & 0.64 & 26.82 \\
$\mathrm{THbO}_{2}$ & $45.90 \pm 18.63$ & $47.79 \pm 17.56$ & 0.77 & 18.55 \\
$\mathrm{MaxHbO}_{2}$ & $16.56 \pm 4.66$ & $15.85 \pm 4.46$ & 0.67 & 16.29 \\
MaxHbT & $17.72 \pm 6.08$ & $16.01 \pm 4.42$ & 0.37 & 24.70 \\
THbT & $19.90 \pm 2.88$ & $20.69 \pm 6.38$ & 0.71 & 12.25 \\
$\begin{array}{l}\text { Inc. rate to } \\
\text { max HbO }\end{array}$ & $1.06 \pm 0.52$ & $0.85 \pm 0.38$ & 0.21 & 41.94 \\
$\begin{array}{l}\text { Inc. rate to } \\
\text { max HbT }\end{array}$ & $0.73 \pm 0.40$ & $0.60 \pm 0.45$ & 0.40 & 50.17 \\
$\begin{array}{l}\text { AUC HbO } \\
\text { AUC HbR }\end{array}$ & $1053.21 \pm 740.53$ & $1131.97 \pm 838.85$ & 0.78 & 33.89 \\
AUC HbT & $1385.63 \pm 929.66$ & $1897.82 \pm 836.57$ & 0.19 & 48.47 \\
\hline
\end{tabular}

subjects computed using NIRS and DOT. NIRS calculations are noisier than DOT reconstructions, despite using the same filtering techniques in both methods. One reason might be that singlechannel measurements are more susceptible to systematic errors, such as position-dependent differences in muscle oxygenation or probe localization and interobserver reproducibility. On the other hand, DOT samples a larger tissue volume. Averaging over a large number of voxels also smooths the response. Furthermore, the image reconstruction method for DOT implements regularization that further improves the SNR. ${ }^{8}$

Figure 5(a) shows the volume averaged $\mathrm{HbO}_{2}, \mathrm{HbR}$, and $\mathrm{HbT}$ for a representative subject while Fig. 5(b) shows a tomographic reconstruction for $\mathrm{HbO}_{2}$ at its maximum value $(t=516 \mathrm{~s})$. The heterogeneity of tissue is evident, and this has been reported in similar studies involving two-dimensional images of venous occlusion tests. ${ }^{48}$ Furthermore, spatial dependence of the hemodynamic responses in the forearm has also been reported in nerve stimulation studies ${ }^{49}$ and in exercising hand in the reflectance ${ }^{50}$ and transmittance ${ }^{51}$ modes. This variability that occurs in all three spatial directions may contribute to diminished repeatability if the probe location is not consistent across examinations.

NIRS and DOT calculations have clear methodological differences, both prone to systematic errors. For NIRS, the key parameter is the DPF, which corrects for the effect of scattering in tissue and therefore is wavelength and tissue dependent. This variable has been the subject of several investigations, and there is an agreement on its main characteristics at population levels. ${ }^{29-31,52}$ However, in most of the cases, DPF is not calculated as part of the arterial/venous occlusion protocol, and calculations are based on data and tables available in the literature.

The techniques used in DOT are more complex and also susceptible to systematic errors such as parameterization of optical parameters, initial guess, or reconstruction convergence criteria. In this study, a differential approach was followed, which has demonstrated to be insensitive to boundary effects and the medium's initial guess. ${ }^{36}$ On the other hand, the major disadvantage is that it is not possible to determine the absolute distribution of optical parameters, but only the change of absorption or diffusion from a given baseline.

In general, our results show time-based parameters have excellent repeatability. These parameters have shown great promise in distinguishing between healthy volunteers and patients with PAD and diabetes. ${ }^{16,17}$ For these patient groups, the reactive hyperemic response showed delayed times of recovery. Parameters derived from $\mathrm{HbO}_{2}$ are also the most repeatable, and this has been observed by different groups. ${ }^{16,20,21}$

\subsection{Regions of Hemodynamic Consistence}

The availability of 3-D maps allows the selection of more specific areas of interest. Selection techniques, either manual or automatic, are available and have been shown to enhance the response by improving the signal-to-noise ratio. Wang ${ }^{53}$ used

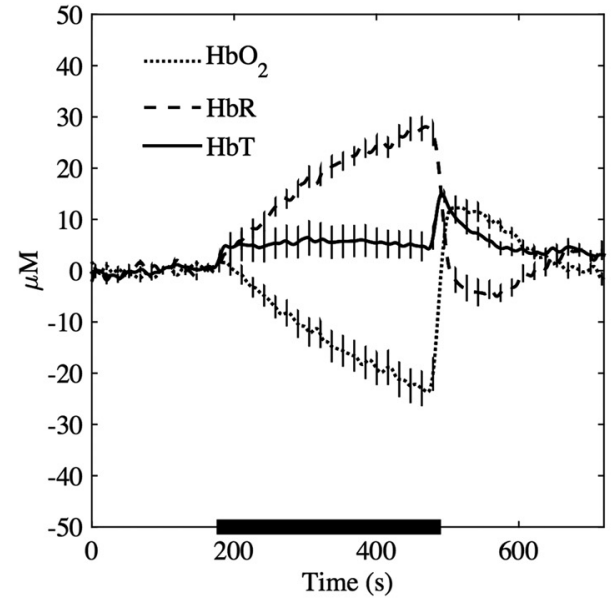

(a)

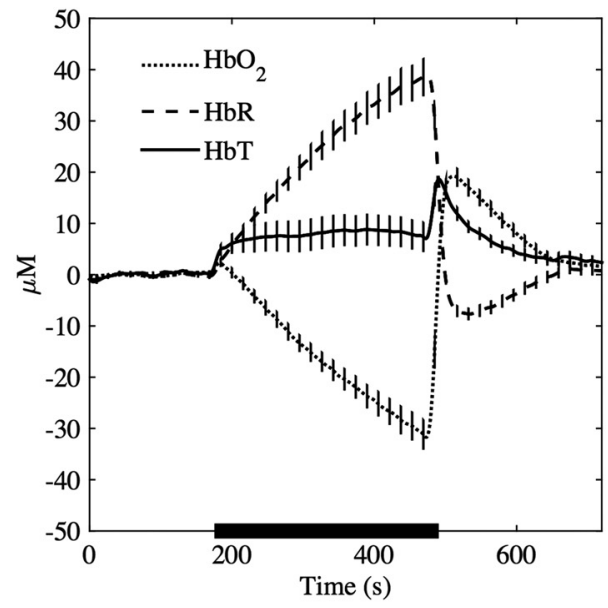

(b)

Fig. 4 Average (solid lines) and standard deviation (vertical bars) of $\mathrm{HbO}_{2}, \mathrm{HbR}$, and $\mathrm{HbT}$ responses across all subjects in the first experiment obtained using (a) NIRS spectroscopy and (b) DOT. 


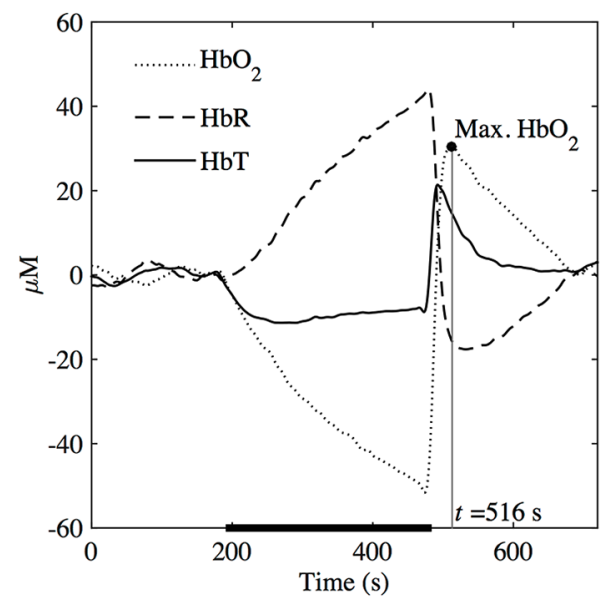

(a)

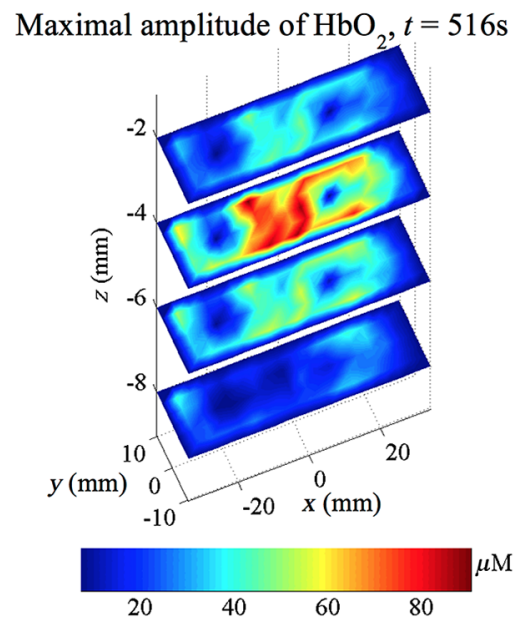

(b)

Fig. 5 (a) Typical hemodynamic responses of oxygenated $\left(\mathrm{HbO}_{2}\right)$, de-oxygenated $(\mathrm{HbR})$ and total hemoglobin $(\mathrm{HbT})$ and (b) $\mathrm{HbO}_{2}(x, y, z, t)$ at $t=516 \mathrm{~s}$, i.e., the time average $\mathrm{HbO}_{2}$ reaches maximum.

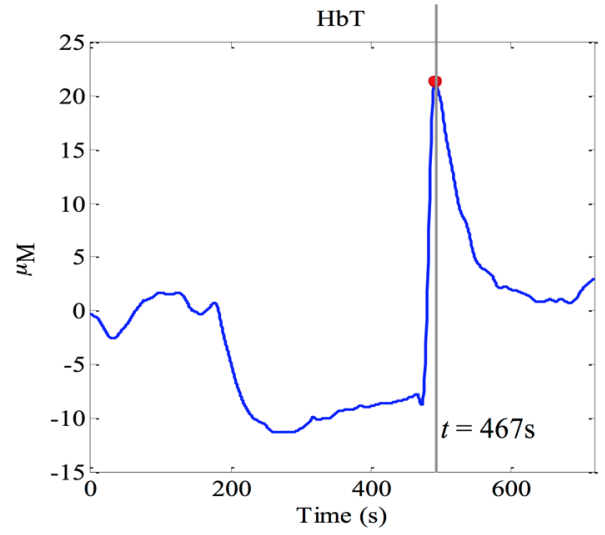

(a)

Correlation coefficients $\rho\left(x_{i}, y_{i}, z_{i}\right)$ between $\operatorname{HbT}_{i}(t)$ and $\mathrm{HbT}_{\max }(t)$

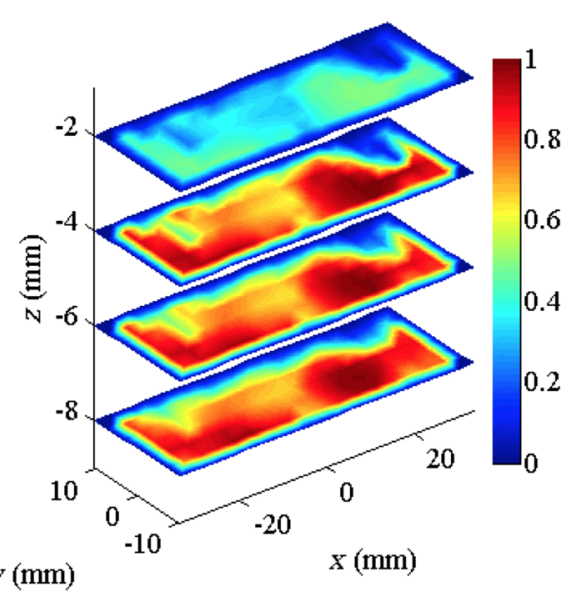

(c)
$\mathrm{HbT}, t=467 \mathrm{~s}$

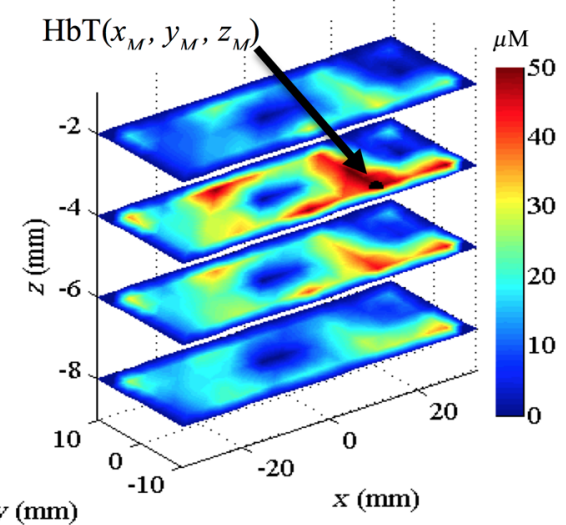

(b)

Correlation coefficients $\rho\left(x_{i}, y_{i}, z_{i}\right)$ between $\mathrm{HbT}_{i}(t)$ and $\mathrm{HbT}_{\text {mean }}(t)$

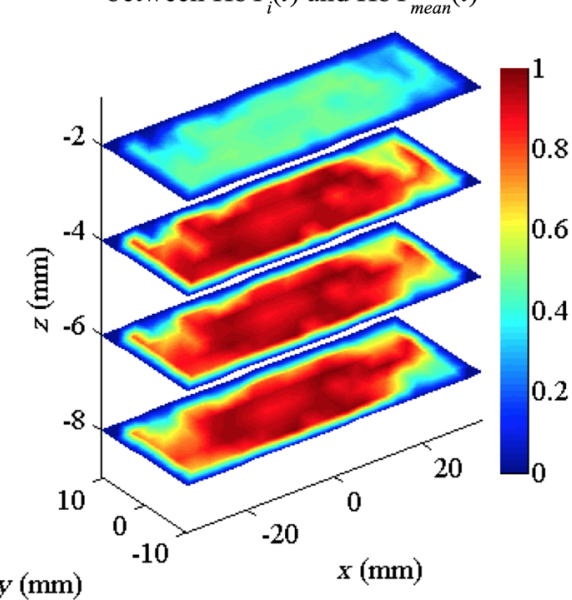

(d)

Fig. 6 (a) Total hemoglobin curve $(\mathrm{HbT})$ for a healthy subject; the point at maximal $\mathrm{HbT}(t=467 \mathrm{~s})$ is marked with a point. (b) 3-D map of $\mathrm{HbT}(x, y, z)$ at the time of maximal $\mathrm{HbT}$. The node with maximum contribution to the $\mathrm{HbT}$ response, $\mathrm{HbT}\left(x_{M}, y_{M}, z_{M}\right)$, is indicated by the arrow and its time response is denoted with $\mathrm{HbT}_{\max }(t)$. (c) 3-D map of correlation coefficients $\rho(x, y, z)$ computed between $\mathrm{HbT}_{i}(t)$ at each node location $\left(x_{i}, y_{i}, z_{i}\right)$ and $\mathrm{HbT}_{\max }(t)$. (d) 3-D map of correlation coefficients $\rho(x, y, z)$ computed between $\mathrm{HbT}_{i}(t)$ at each node location $\left(x_{i}, y_{i}, z_{i}\right)$ and $\mathrm{HbT}_{\text {mean }}(t)$. 
a binarized segmentation technique to select the regions with the dominant response, while in another study by Cuccia et al., ${ }^{54}$ regions with large vessels were avoided to focus on regions containing only microvasculature. Recently, Khalil et al. ${ }^{55}$ employed correlation analysis to define regions of temporal consistency that correlate significantly with the averaged HbT. Their results showed some differences in the evolution of HbT between a healthy volunteer and a patient with PAD, which were not evident from the average signals alone.

The best selection strategy is likely to be disease-dependent, and for this reason, we did not attempt to develop one based only on healthy volunteer subjects. However, to illustrate the potential advantages of DOT compared with NIRS, we carried out the following simple analysis:
Step 1. Compute the average total hemoglobin time series over the ROI, denoted by $\operatorname{HbT}_{\mathrm{ROI}}(t)$, and determine the time point satisfying

$$
\operatorname{HbT}_{\mathrm{ROI}}\left(t_{\max }\right)=\max \left[\operatorname{HbT}_{\mathrm{ROI}}(t)\right] .
$$

This point is located at $t_{\max }=467 \mathrm{~s}$ [Fig. 6(a)].

Step 2. Determine the node $\left(x_{M}, y_{M}, z_{M}\right)$ satisfying

$$
\operatorname{HbT}\left(x_{M}, y_{M}, z_{M}, t\right)=\max [\operatorname{HbT}(x, y, z, t)]
$$

for $t=467 \mathrm{~s}$ [Fig. 6(b)].

Step 3. For each node $\left(x_{i}, y_{i}, z_{i}\right)$ within the ROI, compute the cross-correlation between $\operatorname{HbT}\left(x_{M}, y_{M}, z_{M}, t\right)=$ $\operatorname{HbT}_{\text {max }}(t)$ and $\operatorname{HbT}\left(x_{i}, y_{i}, z_{i}, t\right)=\operatorname{HbT}_{i}(t)$ using

$\rho\left(x_{i}, y_{i}, z_{i}\right)=\frac{\sum_{k=1}^{N}\left[\mathrm{HbT}_{i}(k)-\mathrm{H}_{\overline{\mathrm{b}}} \mathrm{T}_{i}\right]\left[\mathrm{HbT}_{\max }(k)-\mathrm{H}_{\overline{\mathrm{b}}} \mathrm{T}_{\max }\right]}{\sum_{k=1}^{N} \sqrt{\left[\mathrm{HbT}_{i}(k)-\mathrm{HbT}_{i}\right]^{2}} \sum_{t=0}^{N-1} \sqrt{\left[\mathrm{HbT}_{\mathrm{ref}}(k)-\mathrm{HbT}_{\max }\right]^{2}}}$,

where $N$ is the total number of samples and the bar over each variable denotes the time average over the duration of the experiment. The analysis was done on the entire experiment to illustrate the different dynamic signatures that can be obtained when different reference signals are used. Note also that $\operatorname{HbT}_{\text {max }}(t)$ is not necessarily the time series with the highest HbT across the experiment.

The resulting 3-D correlation map $\rho(x, y, z)$, shown in Fig. 6(c), indicates very strong correlation $\left(\rho_{i}>0.9\right)$ with the reactive hyperemic response $\mathrm{HbT}_{\text {max }}(t)$ for nodes located at a depth $>\sim 2 \mathrm{~mm}$, which largely correspond to muscle tissue.

In contrast, the correlation coefficients for nodes located in the superficial layer (skin) are very low $\left(\rho_{i} \leq 0.4\right)$. A different correlation map was computed using as a reference the averaged HbT signal over the ROI, denoted $\operatorname{HbT}_{\mathrm{ROI}}(t)$.

The corresponding 3-D correlation map, shown in Fig. 6(d), also exhibits strong correlation for nodes $\left(\rho_{i}>0.9\right)$ located bellow the skin layer. The correlation maps can be used to define tissue compartments with similar hemodynamic profiles. For example, regions of hemodynamic consistency (RHC) can be defined based on the correlation maps shown in Fig. 6(c) and 6(d) by selecting all nodes with correlation coefficient $\rho \geq 0.9$.

The resulting RHCs are shown in Fig. 7(a); the red and green volumes indicate the regions with high correlation $(\rho \geq 0.9)$ with the $\mathrm{HbT}_{\text {mean }}$ and $\mathrm{HbT}_{\text {max }}(t)$, respectively. The blue volume represents the intersection between the two RHC. The average HbT time series for each RHC are shown in Fig. 7(b) together with the averaged HbT over the entire ROI $\left[\operatorname{HbT}_{\mathrm{ROI}}(t)\right]$.

Interestingly, while the three signals are different before the end of the occlusion period, after the cuff is released only the region correlated to $\mathrm{HbT}_{\text {max }}(t)$ is still distinct compared with the average signal over the entire ROI. This tissue "compartment" identified by our analysis [Fig. 7(a)] appears to exhibit extensive reactive hyperemia both in terms of significantly increased blood flow relative to the baseline as well as duration of hyperemia.

The DOT-estimated MaxHbT and $\mathrm{MaxHbO}_{2}$ also have good reproducibility (ICC $=0.69$ and $\mathrm{ICC}=0.99$, respectively), suggesting that an RHC identified based on $\operatorname{HbT}_{\max }(t)$ could

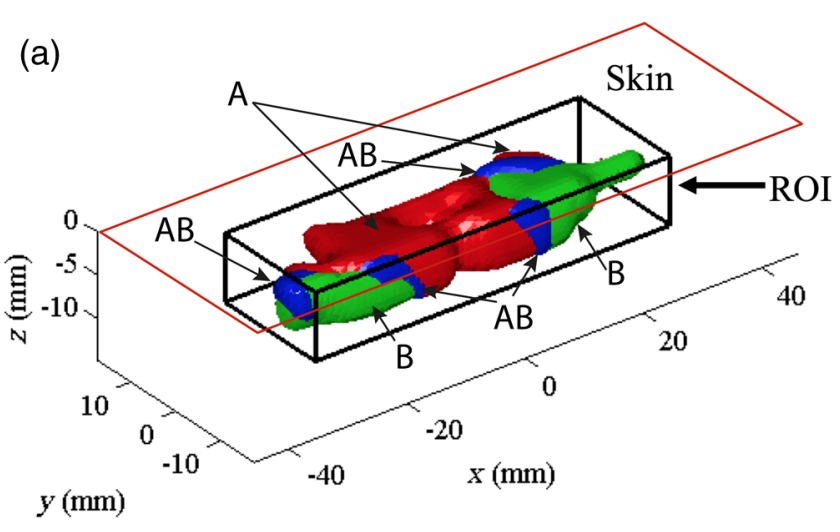

(b)

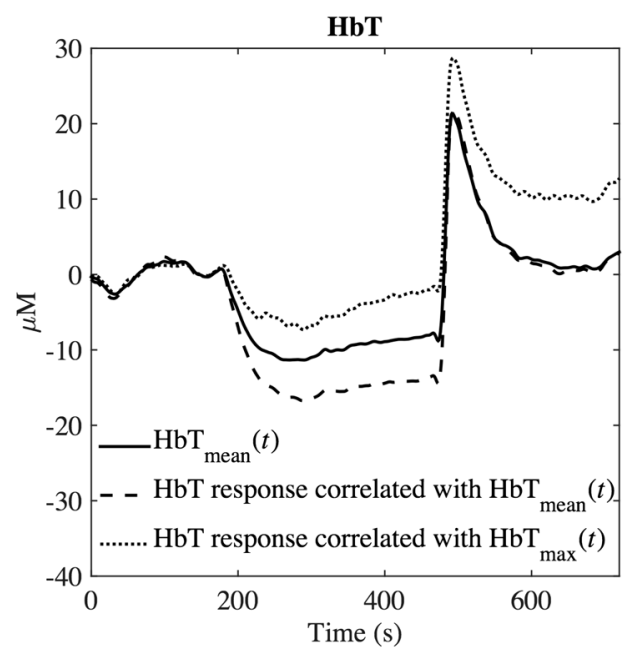

Fig. 7 (a) Compartments defined by the two RHC: the A and B volumes indicate the regions with high correlation $(\rho \geq 0.9)$ with the $\mathrm{HbT}_{\text {mean }}(t)$ and $\mathrm{HbT}_{\text {max }}(t)$, respectively. The $\mathrm{AB}$ represent the intersection between the the $A$ and $B$ regions. The boundaries of the $R O I$ are denoted with the black box. (b) Total hemoglobin averaged over the entire ROI $\left[\mathrm{HbT}_{\text {mean }}(t)\right]$ is indicated with the solid line. The dashed and dotted lines denote the average $\mathrm{HbT}$ response of all the nodes with high correlation $(\rho \geq 0.9)$ with $\mathrm{HbT}_{\text {mean }}(t)$ and $\mathrm{HbT}_{\text {max }}(t)$, respectively. 
(a)

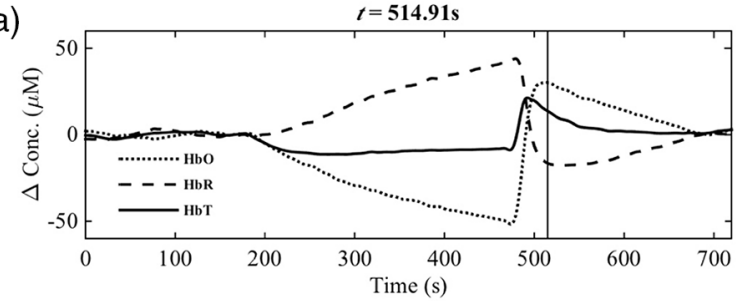

(b)

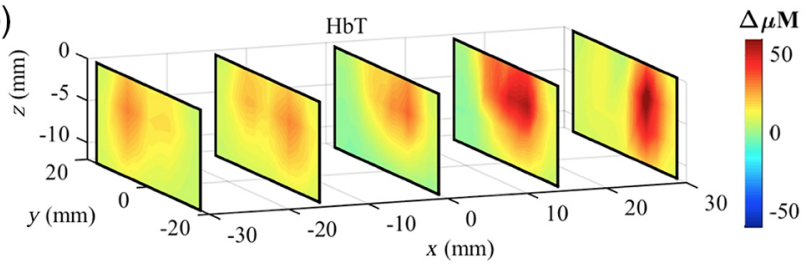

Fig. 8 (a) Dynamical changes of $\mathrm{HbO}_{2}$ (dotted line), $\mathrm{HbR}$ (dashed line), and $\mathrm{HbT}$ (solid line) for a healthy volunteer. (Video 1, top panel) The vertical line indicates the specific time point where a tomographic map is displayed in the lower panel. (b) Visualization of volumetric changes of $\mathrm{HbT}$ (video 1, bottom panel) using $y-z$ slice planes located at $x=-30,-15,0,15$, and $30 \mathrm{~mm}$. (Video 1, MPEG-4, $941 \mathrm{~KB})$ [URL: http://dx.doi.org/10.1117/1.JBO.21.6.066012.1].

be a good candidate to focus on in future studies that aim to distinguish between healthy volunteers and patients with vascular disorder.

In contrast, the relatively poor reproducibility of MaxHbT measured using NIRS (ICC $=0.37$ ), which clearly limits its diagnostic potential, highlights the challenges posed by the spatial and temporal heterogeneity of tissue oxygenation and hemodynamics when assessing endothelial function.

To further illustrate the advantage of using DOT to resolve the spatiotemporal properties of the hemodynamic response, we created a short movie (Fig. 8) showing the reconstructed HbT changes in different slice planes along the $x$ axis.

\section{Conclusions}

This study shows that DOT achieves excellent reproducibility of key PORH parameters. These parameters include muscle oxygen consumption $\left(\mathrm{mVO}_{2}\right)$, time to maximal $\mathrm{HbO}_{2}\left(\mathrm{THbO}_{2}\right)$, maximal $\mathrm{HbO}_{2}\left(\mathrm{MaxHbO}_{2}\right)$, and time to maximal $\mathrm{HbT}$ $(\mathrm{THbT})$. Although a direct comparison of these parameters may be enough to distinguish between healthy volunteers and patients with vascular disease, our analysis suggests that obtaining reliable signatures of vascular disease may require first the identification of an appropriate RHC. This is only possible if a full volumetric reconstruction of hemodynamics, as that provided by DOT, is available for the particular ROI. The choice of an appropriate RHC is beyond the scope of this study, and it is the subject of future research.

The availability of volumetric hemodynamic parameters clearly offers more opportunities for the analysis and characterization of PORH and warrants further efforts to evaluate DOT's potential to measure endothelial function in a clinical environment.

Despite the increased complexity of the instrumentation and reconstruction algorithms used to implement DOT, there are many examples of inexpensive portable and wearable DOT instruments. ${ }^{56}$ The availability of freely available software such as NIRFAST ${ }^{57}$ and TOAST ${ }^{58}$ also encourages the development of DOT-based technology. The use of reduced-order models ${ }^{14}$ to speed up the reconstruction process makes it now possible to perform analyses in real-time using mobile devices with modest computational resources.

Overall, the inherent advantages of DOT compared with other imaging modalities, combined with the availability of algorithms and portability of the instrumentation, makes DOT an ideal method for routinely and noninvasively assessing the cardiovascular function, inside and outside the hospital.

\section{Acknowledgments}

The authors gratefully acknowledge that this work was supported by the University of Sheffield as part of the "Engineering for Life" 2022 Futures Project and by EPSRC grants EP/H00453X/1 (S.A.B. and D.C.) and GR/T01006/01 (D.C.), by BBSRC grant BB/K010123/1 (S.A.B. and D.C.) and by an ERC Advanced Investigator Grant (S.A.B.). E.E.V. R. gratefully acknowledges the support from a grant from the Mexican National Research Council for Science and Technology (CONACYT).

\section{References}

1. G. A. Roth et al., "Global and regional patterns in cardiovascular mortality from 1990 to 2013," Circulation 132(17), 1667-1678 (2015).

2. Cardiovascular-Disease-Team, Cardiovascular Disease Outcomes Strategy, Department of Health, London, p. 89 (2013).

3. D. A. Benaron et al., "Noninvasive methods for estimating in vivo oxygenation," Clin. Pediatr. 31(5), 258-273 (1992).

4. M. Ferrari, M. Muthalib, and V. Quaresima, "The use of near-infrared spectroscopy in understanding skeletal muscle physiology: recent developments," Philos. Trans. R Soc. A 369(1955), 4577-4590 (2011).

5. M. Cope and D. T. Delpy, "System for long-term measurement of cerebral blood and tissue oxygenation on newborn-infants by nearinfrared trans-illumination," Med. Biol. Eng. Comput. 26(3), 289-294 (1988).

6. F. F. Jobsis, "Noninvasive, infrared monitoring of cerebral and myocardial oxygen sufficiency and circulatory parameters," Science 198(4323), 1264-1267 (1977).

7. D. A. Boas, A. M. Dale, and M. A. Franceschini, "Diffuse optical imaging of brain activation: approaches to optimizing image sensitivity, resolution, and accuracy," Neuroimage 23, S275-S288 (2004).

8. A. P. Gibson, J. C. Hebden, and S. R. Arridge, "Recent advances in diffuse optical imaging," Phys. Med. Biol. 50(4), R1-R43 (2005).

9. A. Villringer and B. Chance, "Non-invasive optical spectroscopy and imaging of human brain function," Trends Neurosci. 20(10), 435-442 (1997)

10. M. C. P. Van Beekvelt et al., "Performance of near-infrared spectroscopy in measuring local $\mathrm{O} 2$ consumption and blood flow in skeletal muscle," J. Appl. Physiol. 90(2), 511-519 (2001).

11. D. A. Boas et al., "The accuracy of near infrared spectroscopy and imaging during focal changes in cerebral hemodynamics," Neuroimage 13(1), 76-90 (2001)

12. C. Habermehl et al., "Somatosensory activation of two fingers can be discriminated with ultrahigh-density diffuse optical tomography," NeuroImage 59(4), 3201-3211 (2012).

13. G. Strangman, M. A. Franceschini, and D. A. Boas, "Factors affecting the accuracy of near-infrared spectroscopy concentration calculations for focal changes in oxygenation parameters," Neuroimage 18(4), 865-879 (2003).

14. E. E. Vidal-Rosas et al., "Reduced-order modeling of light transport in tissue for real-time monitoring of brain hemodynamics using diffuse optical tomography," J. Biomed. Opt. 19(2), 026008 (2014).

15. M. Vardi and A. Nini, "Near-infrared spectroscopy for evaluation of peripheral vascular disease. a systematic review of literature," Eur. $J$. Vasc. Endovascular Surg. 35(1), 68-74 (2008).

16. T. Jarm et al., "Postocclusive reactive hyperemia in healthy volunteers and patients with peripheral vascular disease measured by three noninvasive methods," in Advances in Experimental Medicine and Biology, 
J. F. Dunn and H. M. Swartz, Eds., pp. 661-669, Springer, Boston, Massachusetts (2003).

17. R. Kragelj et al., "Parameters of postocclusive reactive hyperemia measured by near infrared spectroscopy in patients with peripheral vascular disease and in healthy volunteers," Ann. Biomed. Eng. 29(4), 311-320 (2001).

18. M. Gayda et al., "Muscle VO2 and forearm blood flow repeatability during venous and arterial occlusions in healthy and coronary heart disease subjects," Clin. Hemorheol. Microcirculation 59(2), 177-183 (2015).

19. R. C. Mesquita et al., "Diffuse optical characterization of an exercising patient group with peripheral artery disease," J. Biomed. Opt. 18(5), 057007 (2013).

20. S. Lacroix et al., "Reproducibility of near-infrared spectroscopy parameters measured during brachial artery occlusion and reactive hyperemia in healthy men," J. Biomed. Opt. 17(7), 077010 (2012).

21. R. Kragelj, T. Jarm, and D. Miklavcic, "Reproducibility of parameters of postocclusive reactive hyperemia measured by near infrared spectroscopy and transcutaneous oximetry," Ann. Biomed. Eng. 28(2), 168-173 (2000).

22. M. A. Khalil et al., "Detection of peripheral arterial disease within the foot using vascular optical tomographic imaging: a clinical pilot study," Eur. J. Vasc. Endovascular Surg. 49(1), 83-89 (2015).

23. A. Torricelli et al., "Functional brain imaging by multi-wavelength timeresolved near infrared spectroscopy," Opto-electron. Rev. 16(2), 131135 (2008).

24. T. Muehlemann, D. Haensse, and M. Wolf, "Wireless miniaturized in-vivo near infrared imaging," Opt. Express 16(14), 10323-10330 (2008).

25. K. J. Kek et al., "Optical imaging instrument for muscle oxygenation based on spatially resolved spectroscopy," Opt. Express 16(22), 1817318187 (2008)

26. C. H. Schmitz et al., "Dynamic studies of small animals with a fourcolor diffuse optical tomography imager," Rev. Sci. Instrum. 76(9), 094302 (2005).

27. M. Cope, The Development of a Near-Infrared Spectroscopy System and Its Application for Noninvasive Monitoring of Cerebral Blood and Tissue Oxygenation, University College London, London (1991).

28. D. T. Delpy et al., "Estimation of optical pathlength through tissue from direct time of flight measurement," Phys. Med. Biol. 33(12), 1433-1442 (1988).

29. P. Van der Zee et al., "Experimentally measured optical pathlengths for the adult head, calf and forearm and the head of the newborn infant as a function of inter optode spacing," Adv. Exp. Med. Biol. 316, 143-153 (1992).

30. A. Duncan et al., "Optical pathlength measurements on adult head, calf and forearm and the head of the newborn-infant using phase-resolved optical spectroscopy," Phys. Med. Biol. 40(2), 295-304 (1995).

31. M. Ferrari et al., "Time-resolved spectroscopy of the human forearm," J. Photochem. Photobiol. B 16(2), 141-153 (1992).

32. S. R. Arridge, "Methods in diffuse optical imaging," Philos. Trans. $R$. Soc. A 369(1955), 4558-4576 (2011).

33. M. S. Patterson, B. Chance, and B. C. Wilson, "Time resolved reflectance and transmittance for the noninvasive measurement of tissue optical-properties," Appl. Opt. 28(12), 2331-2336 (1989).

34. M. Schweiger et al., "The finite element method for the propagation of light in scattering media: boundary and source conditions," Med. Phys. 22(11), 1779-1792 (1995).

35. S. R. Arridge, "Optical tomography in medical imaging," Inverse Prob. 15(2) R41-R93 (1999).

36. Y. L. Pei, H. L. Graber, and R. L. Barbour, "Influence of systematic errors in reference states on image quality and on stability of derived information for dc optical imaging," Appl. Opt. 40(31), 5755-5769 (2001).

37. J. Nocedal and S. Wright, Numerical Optimization, 2nd Ed., Springer, New York (2006).

38. A. Y. Bluestone et al., "Three-dimensional optical tomographic brain imaging in small animals, part 1: hypercapnia," J. Biomed. Opt. 9(5), 1046-1062 (2004).

39. T. Lister, P. A. Wright, and P. H. Chappell, "Optical properties of human skin,” J. Biomed. Opt. 17(9), 090901 (2012).
40. S. L. Jacques, "Optical properties of biological tissues: a review," Phys. Med. Biol. 58(11), R37-R61 (2013).

41. S. R. Arridge and M. Schweiger, "Photon-measurement densityfunctions. 2. Finite-element-method calculations," Appl. Opt. 34(34), 8026-8037 (1995).

42. S. R. Arridge, "Photon-measurement density functions. Part I: analytical forms," Appl. Opt. 34(31), 7395-7409 (1995).

43. G. Q. Yu et al., "Time-dependent blood flow and oxygenation in human skeletal muscles measured with noninvasive near-infrared diffuse optical spectroscopies," J. Biomed. Opt. 10(2), 024027 (2005).

44. Y. L. Pei, H. L. Graber, and R. L. Barbour, "Normalized-constraint algorithm for minimizing inter-parameter crosstalk in DC optical tomography," Opt. Express 9(2), 97-109 (2001).

45. T. A. Baumgartner, "Statistical tools in evaluation," Chapter 2 in Statistical Tools in Evaluation, 3rd Ed., A. S. Jackson, Eds., Houghton Mifflin, London (1987).

46. D. G. Altman, Practical Statistics for Medical Research, p. 623, Chapman \& Hall, London (1999).

47. M. C. P. van Beekvelt et al., "In vivo quantitative near-infrared spectroscopy in skeletal muscle during incremental isometric handgrip exercise," Clin. Physiol. Funct. Imaging 22(3), 210-217 (2002).

48. C. Casavola et al., "Blood flow and oxygen consumption with nearinfrared spectroscopy and venous occlusion: spatial maps and the effect of time and pressure of inflation," J. Biomed. Opt. 5(3), 269-276 (2000).

49. D. K. Chen et al., "Spectral and spatial dependence of diffuse optical signals in response to peripheral nerve stimulation," Biomed. Opt. Express 1(3), 923-942 (2010).

50. M. Maris et al., "Functional near-infrared imaging of deoxygenated hemoglobin during exercise of the finger extensor muscles using the frequency-domain technique," Bioimaging 2(4), 174-183 (1994).

51. E. M. C. Hillman et al., "Time resolved optical tomography of the human forearm," Phys. Med. Biol. 46(4), 1117-1130 (2001).

52. S. J. Matcher, M. Cope, and D.T. Delpy, "In vivo measurements of the wavelength dependence of tissue-scattering coefficients between 760 and $900 \mathrm{~nm}$ measured with time-resolved spectroscopy," Appl. Opt. 36(1), 386-396 (1997).

53. C. Y. Wang et al., "Diffuse optical multipatch technique for tissue oxygenation monitoring: clinical study in intensive care unit," IEEE Trans. Biomed. Eng. 59(1), 87-94 (2012).

54. D. J. Cuccia et al., "Quantitation and mapping of tissue optical properties using modulated imaging," J. Biomed. Opt. 14(2), 024012 (2009).

55. M. A. Khalil et al., "Dynamic diffuse optical tomography imaging of peripheral arterial disease," Biomed. Opt. Express 3(9), 2288-2298 (2012).

56. F. Scholkmann et al., "A review on continuous wave functional nearinfrared spectroscopy and imaging instrumentation and methodology," NeuroImage 85, 6-27 (2014).

57. H. Dehghani et al., "Near infrared optical tomography using NIRFAST: algorithm for numerical model and image reconstruction," Cоттип. Numer. Methods Eng. 25(6), 711-732 (2009).

58. M. Schweiger and S. Arridge, "The Toast++ software suite for forward and inverse modeling in optical tomography," J. Biomed. Opt. 19(4), 040801 (2014).

Ernesto E. Vidal-Rosas is a research associate at the University of Sheffield. He received his BEng and MSc degrees in electronic engineering from the Orizaba Institute of Technology and the National Centre for Research and Technology Development Cuernavaca in 2003 and 2006, respectively, and his PhD degree from the University of Sheffield in 2011. His main research interests include the development and application of novel methods for image reconstruction and analysis for diffuse optical tomography.

Stephen A. Billings is a professor in the Department of Automatic Control and Systems Engineering at the University of Sheffield and leads the Signal Processing and Complex Systems research group. His research interests include system identification and information processing for nonlinear systems, narmax methods, model validation, prediction, spectral analysis, adaptive systems, nonlinear systems analysis, wavelets, machine vision, cellular automata, spatiotemporal 
systems, EEG, fMRI and optical imagery of the brain, synthetic biology, crystal growth, and related fields.

Timothy Chico is reader in cardiovascular medicine at the University of Sheffield. He qualified in medicine from Leeds Medical School before undertaking an MD at the University of Sheffield. He previously held a GSK clinician scientist fellowship and works in the Bateson Centre lot the University of Sheffield. His research interests are in the effect of blood flow on vascular remodelling.
Daniel Coca is a professor at the University of Sheffield. He received his MEng degree in electrical engineering from Transilvania University of Brasov in 1993 and his PhD degree in automatic control and systems engineering from the University of Sheffield in 1997. His research interests include modeling, analysis, and control of complex systems, inverse problems, diffuse optical tomography and biological data analysis using reconfigurable computers. 